Article

\title{
Investigating on the Iconic Gas Compositions Produced by Low-Temperature Heating Cotton
}

\author{
Hetao Su ${ }^{1,2}$, Jingdong Shi ${ }^{1}$, Huaijun $\mathrm{Ji}^{1,2, *}{\text { Jiake } \mathrm{Li}^{3} \text { and Jingru Fan }}^{1}$ \\ 1 School of Engineering and Technology, China University of Geosciences (Beijing), Beijing 100083, China; \\ h.su@cugb.edu.cn (H.S.); 2102190094@cugb.edu.cn (J.S.); 2102190103@cugb.edu.cn (J.F.) \\ 2 Key Laboratory of Deep Geodrilling Technology, Ministry of Land and Resources, China University of \\ Geosciences (Beijing), Beijing 100083, China \\ 3 School of Reliability and Systems Engineering, Beihang University, Beijing 100191, China; \\ ljk7170@buaa.edu.cn \\ * Correspondence: jhjun2015@cugb.edu.cn
}

Received: 1 May 2020; Accepted: 27 May 2020; Published: 29 May 2020

\begin{abstract}
This study aims at achieving the generation laws of the iconic gas compositions produced during the process of the cotton smoldering. A mini tube furnace was used to heat a long-staple cotton sample from Xinjiang, China, and a gas chromatography-mass spectrometer (GC/MS) was applied to analyze the produced organic and inorganic gas composition at different low temperatures ranging from $95^{\circ} \mathrm{C}$ to $185^{\circ} \mathrm{C}$. Besides, a thermogravimetric experiment under air atmosphere was done in order to verify the correctness of the inferences. The pathways of product generation by heating cotton were set forth, including the depolymerization of the cotton cellulose, the sequential generation of coke, low molecular weight products, long chain carboxylic acids, levoglucosenone, and acetone at $125^{\circ} \mathrm{C}$, and the generation of hydrogen at $95^{\circ} \mathrm{C}$, carbon dioxide, carbon monoxide at $145^{\circ} \mathrm{C}$, and methane during the heating process. The results showed that the alkanes, furans, alkenes, aldehydes, hydrazines, and acids could not be regarded as the iconic gas compositions because of their little proportion, the joint detection of the methane and hydrogen could be used to predicate the smoldering, and the acetone and carbon monoxide could be used to confirm the smoldering stage. The results of the thermogravimetric experiment are consistent with theoretical analysis, indicating that analyses are reliable. This work will provide significant practice foundation for the early warning and prevention of cotton fires.
\end{abstract}

Keywords: cotton smoldering; organics and inorganics; generation laws; methane; acetone; carbon monoxide

\section{Introduction}

As a natural resource, cotton has been the most widely used material in clothing, household, and many industrial and military supplies because of its excellent water absorption and air permeability [1]. Except food, cotton is the widest planting crop [2]. The content of cellulose in cotton reaches up to $93.87 \%$. The cellulose is easy burnt with the burning point of about $160{ }^{\circ} \mathrm{C}$ [1]. Smoldering is a slow, low temperature, flameless form of combustion [3]. After a tinder dropped into a cotton bale, there will be a slow burning inside the cotton bale, because of the lack of oxygen and insufficient burning, which is called a smoldering. There is no smoke or flame during smoldering, leading to a hard prevention. Compared with burning, the undetectable smoldering is more dangerous. Smoldering causes death and lose of money during the storage, loading, and transportation process of cotton $[3,4]$. In the classification of dangerous goods in China, cotton belongs to the fourth category of "inflammable solid" spontaneous combustion articles, encounter wet inflammable articles. Spontaneous 
combustion fires inside bales are more difficult to prevent and detect because they look like smoldering fires that slowly spread. These fires often begin to spread by days or weeks before they are detected, making it more difficult to mitigate and extinguish them because of their size and location [5]. It is of great practical significance to study the low temperature combustion characteristics of cotton in order to reduce the loss of cotton bale caused by the fire resulting from smoldering. By analyzing the gas-producing components of cotton under low temperature heating, the gas types, gas volumes and the relative volume fraction of the corresponding gas can be obtained. The temperature of cotton can be predicted by the type of gas.

The recent researches focus on the factors, reasons, and simulation of the process from smoldering to burning. Travers et al. [6] studied the effect of breathability on the smoldering characters of cotton, they found the breathability had no obvious effect on the smoldering temperature, but it had a great influence on the smoldering time. Wakelyn et al. [7] put a small smoldered cotton bale in the center of a bigger bale to simulate the inner fire of cotton. The results showed when the density of cotton bale increased to $225 \mathrm{~kg} / \mathrm{m}^{3}$, the air spreading into the cotton bale did not meet the requirement of burning. Donaldson et al. [8] discussed the effect of washing on the smoldering properties of cotton and found that the way to wash smoldering cotton before fabricating cotton fabrics or yarns and fibers significantly reduced the smoldering propensity of cotton. Kellogg et al. [9] studied the smoldering process of porous fiber, showing that the smoldering of fiber needed enough oxygen and heat to keep the smoldering. The smoldering appeared when the number of sodium ion of fiber increased to a certain level. With the increasing of sodium ion, the ignition time of fiber is shortened. Li et al. [10] considered that the degree of smoldering had a correlation with moisture content. With the increasing of moisture content, the smoldering speed of cotton slowed down. Experimental studies on the smoldering combustion of cotton with different moisture content also reached a similar conclusion, that is, the smoldering combustion process of cotton delayed and the high temperature duration of smoldering cotton prolonged because of higher moisture [11]. Hagen et al. [12] studied the transition from smoldering to combustion of short cotton samples with asymmetric boundary conditions. The results indicated that the transition from the smoldering to combustion was affected by the boundary conditions. Furthermore, in the case of lightweight concrete blocks, the transition from smoldering to flaming occurred when smoldering and secondary char oxidation coexisted. Recent research by some domestic researchers found that it contained two stages without wind during smoldering spread of creeping. From the free surface to the internal fuel concurrent with the wind, only one main simultaneous smoldering front was observed [13].

The investigation of iconic gas compositions has a great help to identify burning stages and prevent fire accidents $[14,15]$. Most researchers focus on using iconic gas to forecast spontaneous coal combustion [16-18], while they study less about the iconic gas during the smoldering of cotton. The most common reference gases used to indicate fire and fire characteristics are carbon monoxide and carbon dioxide, especially carbon monoxide emissions in smoldering fires with insufficient oxygen [5]. Some researchers studied the correlation between the volume of carbon monoxide and other factors [19]. Previous studies confirmed that the carbon monoxide appeared and escaped at $120{ }^{\circ} \mathrm{C}$ during the cotton smoldering. At the early stage of smoldering, the carbon monoxide speeded slowly along the gap from the smoldering point. The carbon monoxide concentration and the size of gap had an inverse relationship. The carbon monoxide was a kind of important iconic gas composition, but the monition of only one iconic gas composition might not estimate the smoldering stage of cotton accurately. The smoldering stage could be estimated more accurately according to the generation laws of different gas compositions.

It can be found that most of the above-mentioned studies reported the influence of breathability, oxygen, heat, water content, metal ions, boundary conditions, or other factors on the smoldering of cotton or simulate the combustion process, there was basically no relevant discussion on how to prevent cotton smoldering and none of the index gases have been studied to predict the cotton smoldering. As a continuation of previous studies outlined above, a mini tube furnace was used 
to heat cotton at air condition in this work. A gas chromatography-mass spectrometer (GC/MS) was used to study the generation laws of produced gas compositions, with supporting detectors for composition separation and detection of gaseous products at different temperatures. Furthermore, a thermogravimetric experiment was conducted to analyze the reliability of the theoretical analysis. The iconic gas compositions were proposed to predict the cotton smoldering. This research will promote not only the investigation of cotton smoldering process but also cotton fire prevention.

\section{Materials and Methods}

\subsection{Experimental Apparatus}

The mini tube furnace was used in this experiment. The furnace had the advantages of balanced temperature field, adjustable heating rate of $0-20{ }^{\circ} \mathrm{C} / \mathrm{min}$, energy saving with the high purity alumina fiber, etc., which were suitable for the use of this experiment. A rotameter with a setting range of 0-100 $\mathrm{mL} / \mathrm{min}$, which was used to control the flow rate, and a pressure gauge were fixed at the air inlet. An aluminum gas bag with a bulk of $1 \mathrm{~L}$ was connected to the air outlet to collect the gas. The experimental apparatus is shown in Figure 1.

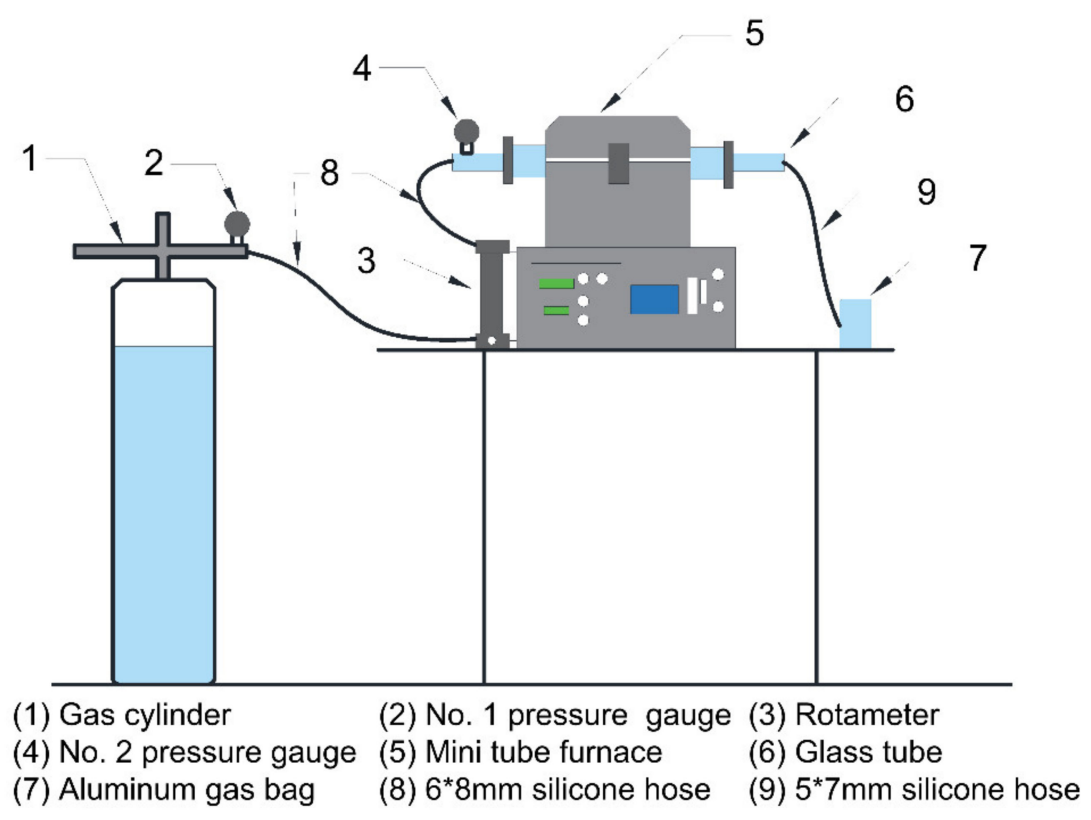

Figure 1. Layout of the experimental apparatus.

\subsection{Heating Cotton and Gas Collection}

At the beginning of the experiments, the apparatus was sealed well. The valve of the gas cylinder was opened, and the air flow rate was set to $30 \mathrm{~mL} / \mathrm{min}$ through controlling the rotameter. The air was injected into the apparatus for a certain time to ensure that the original gas in the tube was evacuated. Then, the mini tube furnace was switched on to set up the heating times and temperatures, as shown in Table 1. The long-staple cotton from Xinjiang, China, whose mass was approximately $15 \mathrm{~g}$, was used as an experiment sample to be put in the glass tube. The cotton was not manually processed. The cotton sample was heated to a certain temperature by the mini tube furnace. Several aluminum gas bags were used to collect the gas at different temperatures. Because of the heating process and heating temperature range of mini tube furnace, there was a deviation for the temperature setting at below $100{ }^{\circ} \mathrm{C}$. The actual available temperatures were $95^{\circ} \mathrm{C}, 105^{\circ} \mathrm{C}, 125^{\circ} \mathrm{C}, 145^{\circ} \mathrm{C}, 165^{\circ} \mathrm{C}$ and $185^{\circ} \mathrm{C}$. After the gas collection was finished, the air was still inserted into the mini tube furnace to decrease the temperature of the mini tube furnace until the temperature was safe for opening. 
Table 1. Theoretical temperature setting.

\begin{tabular}{ccc}
\hline Temperature $\left({ }^{\circ} \mathbf{C}\right)$ & Collection Duration $(\mathbf{m i n})$ & Heating Time $(\mathbf{m i n})$ \\
\hline 85 & 20 & 15 \\
105 & 20 & 15 \\
125 & 20 & 15 \\
145 & 20 & 15 \\
165 & 20 & 15 \\
185 & 20 & 15 \\
\hline
\end{tabular}

\subsection{Gas Composition Analysis}

Gas chromatography is suitable for qualitative and quantitative analysis of volatile organic compounds. According to the peak time and sequence indicated in the chromatogram, the compound can be qualitatively analyzed. According to the peak height and area size, the compound can be quantitatively analyzed. The gas chromatography mass spectrometry whose type number is $6890 \mathrm{~N}-5973 \mathrm{~N}$, produced by Agilent Technologies Inc. was used in this research. The important technical parameters of gas-mass spectrometer are shown in Table 2.

Table 2. Important technical parameters of gas-mass spectrometer.

\begin{tabular}{cc}
\hline Name of Parameters & Parameters \\
\hline Reproducibility of retention time & $<0.008 \%$ \\
Reproducibility of gas chromatography mass spectrometry & $<1 \%$ RSD \\
Electronic pressure control accuracy & $0.001 \mathrm{psi}$ \\
Maximum temperature & $400{ }^{\circ} \mathrm{C}$ \\
Mass range & $1.6-1050 \mathrm{amu}$ \\
Scan rate & $12,500 \mathrm{u} / \mathrm{s}$ \\
\hline
\end{tabular}

Gases from six aluminum gas bags were successively imported to the chromatographic column of a gas chromatography. The gas compositions were separated in the chromatographic column. The categories and concentrations (volume fractions) of organics and inorganics were analyzed through a contrastive analysis in the chromatograms between the known substances and the collected gases. The gas compositions, whose concentrations changed obviously and were easy to be measured, were chosen in this study. The temperatures, average flow rates, durations, and volumes of gas collection are shown in Table 3.

Table 3. Average flow rates, collection durations, and gas collection volumes at different temperatures.

\begin{tabular}{cccc}
\hline Temperature $\left({ }^{\circ} \mathbf{C}\right)$ & Average Flow Rate $(\mathbf{m L} / \mathbf{m i n})$ & Collection Duration $(\mathbf{m i n})$ & Gas Collection Volume $(\mathbf{m L})$ \\
\hline 95 & 30 & 10 & 300 \\
105 & 20 & 20 & 400 \\
125 & 25 & 20 & 500 \\
145 & 25 & 20 & 500 \\
165 & 17 & 13 & 221 \\
185 & 16 & 13 & 208 \\
\hline
\end{tabular}

\section{Results and Discussions}

\subsection{Iconic Gas Compositions}

Table 4 shows the testing results of partial inorganic gases (nitrogen, oxygen, hydrogen, and carbon monoxide). The nitrogen and oxygen made up approximately $76 \mathrm{vol} . \%$ and $20 \mathrm{vol} . \%$ of the gaseous products, respectively. The hydrogen was found at $95{ }^{\circ} \mathrm{C}$, and then it disappeared at $105{ }^{\circ} \mathrm{C}$. The hydrogen occurred again with a concentration of $0.0446 \mathrm{vol} . \%$ at $125^{\circ} \mathrm{C}$. The hydrogen concentration 
decreased to 0 with increasing temperature to $165^{\circ} \mathrm{C}$. The hydrogen was found for the third time with a concentration of $0.0394 \mathrm{vol} . \%$ at $185^{\circ} \mathrm{C}$. The carbon monoxide only occurred at $145^{\circ} \mathrm{C}$.

Table 4. Testing of partial inorganic gases.

\begin{tabular}{ccccc}
\hline \multirow{2}{*}{ Temperature $/{ }^{\circ} \mathbf{C}$} & \multicolumn{3}{c}{ Composition (vol.\%) } \\
\cline { 2 - 4 } & Nitrogen & Oxygen & Hydrogen & Carbon Monoxide \\
\hline 95 & 76.0158 & 20.0321 & 0.0197 & 0 \\
105 & 76.3142 & 20.7831 & 0 & 0 \\
125 & 76.5528 & 20.8694 & 0.0446 & 0 \\
145 & 76.6052 & 20.8847 & 0.0328 & 0.1002 \\
165 & 76.3281 & 20.7723 & 0 & 0 \\
185 & 77.3182 & 20.9654 & 0.0394 & 0 \\
\hline
\end{tabular}

Apart from the nitrogen of $76 \mathrm{vol} . \%$ and the oxygen of $20 \mathrm{vol} . \%$ in the gaseous products, the organic gases made up lower than 4 vol.\%. The percentage of a chromatographic peak area over the total peak area in a chromatograph from the thermionic ionization detector (TID) is regarded as the proportion of the specific gas composition corresponding to the peak. When the percentage of a chromatographic peak area is lower than $0.1 \%$, the corresponding gas composition concentration is lower than $0.004 \mathrm{vol} . \%$, which is a very small volume. Therefore, the organic gas compositions, whose chromatographic peak area is more than $0.1 \%$, are chosen to study, as shown in Table 5 . The proportion of methane in the organic gases was nearly $100 \%$. Thus, the gas composition produced by heating cotton was mainly the methane. The siloxane, cyclic siloxane, acenaphthene, anthracene, and acid had low concentrations, being difficult to be examined.

Table 5. Testing of partial organic gases.

\begin{tabular}{cccc}
\hline Temperature $\left({ }^{\circ} \mathbf{C}\right)$ & CAS Number & Composition Name & Peak Area (\%) \\
\hline 95 & $74-82-8$ & Methane & 99.59 \\
\hline \multirow{2}{*}{105} & $74-82-8$ & Methane & 99.65 \\
& $4076-39-5$ & 1-Methylbenzo[c]phenanthrene & 0.14 \\
\hline \multirow{2}{*}{125} & $74-82-8$ & Methane & 99.11 \\
& $67-64-1$ & Acetone & 0.11 \\
& $540-97-6$ & Dodecamethylcyclohexasiloxane & 0.1 \\
\hline \multirow{3}{*}{145} & $74-82-8$ & Methane & 98.3 \\
& $540-97-6$ & Dodecamethylcyclohexasiloxane & 0.54 \\
& $107-50-6$ & Tetradecamethylcycloheptasiloxane & 0.4 \\
& $556-68-3$ & Hexadecamethylcyclooctasiloxane & 0.26 \\
& $67-64-1$ & Acetone & 0.21 \\
& $541-02-6$ & Cyclopentasiloxane & 0.15 \\
\hline \multirow{2}{*}{165} & $74-82-8$ & Methane & 99.47 \\
& $540-97-6$ & Dodecamethylcyclohexasiloxane & 0.17 \\
& $557-30-2$ & Glyoxime & 0.05 \\
& $3555-47-3$ & Tetrakis (trimethylsilyl) orthosilicate & 0.11 \\
\hline \multirow{2}{*}{185} & $74-82-8$ & Methane & 99.54 \\
\hline
\end{tabular}

\subsection{Generation of the Iconic Gas Compositions}

According to the above testing results of gas compositions, the main organic compositions were methane and acetone. The scholars had found that the long-staple cotton could produce a little acetone at the early stage of smoldering. The mechanism of producing acetone is as follows: The nonvolatile laevoglucose was generated by the depolymerization of the cotton cellulose; the laevoglucose further cracked into coke and low molecular weight products; at the beginning stage of the depolymerization 
less than $150^{\circ} \mathrm{C}$, the cotton cellulose chain suffered a light break, and some circular chains were broken to long chain carboxylic acids; a new compound, called levoglucosenone, was generated because of the intramolecular dehydration and glycosidic bond cleavage under acidic conditions [20-22]; and the acetone was produced through a serious of complicated reactions.

Because of the low temperature, the production of levoglucosenone was little, thus, the production of acetone was little, which was consistent with the little production of acetone from the above testing results. The following reaction (1) occurred when the acetone was not heated completely. As a mid-product, the acetone was not stable, which was also the reason why the production of acetone was little.

$$
\left(\mathrm{CH}_{3}\right)_{2} \mathrm{CO}+\mathrm{O}_{2} \stackrel{\text { Incomplete reaction }}{\longrightarrow} 3 \mathrm{C}+3 \mathrm{H}_{2} \mathrm{O} \uparrow
$$

The main organic composition produced by heating cotton was the methane. The low temperature carbonization of the cellulose mainly occurred at $250^{\circ} \mathrm{C}$. When the temperature was below $250{ }^{\circ} \mathrm{C}$, the carbonization and dehydration occurred, and the water was found in the glass tube. Therefore, the reactions of methane generation could be defined as:

$$
\begin{gathered}
\mathrm{C}+2 \mathrm{H}_{2} \stackrel{\text { Heating }}{\longrightarrow} \mathrm{CH}_{4} \uparrow \\
\mathrm{CO}+3 \mathrm{H}_{2} \stackrel{\text { Heating }}{\longrightarrow} \mathrm{CH}_{4} \uparrow+\mathrm{H}_{2} \mathrm{O} \\
\mathrm{CO}_{2}+4 \mathrm{H}_{2} \stackrel{\text { Heating }}{\longrightarrow} \mathrm{CH}_{4} \uparrow+2 \mathrm{H}_{2} \mathrm{O}
\end{gathered}
$$

The reactions (2), (3) and (4) were all exothermic reactions and entropy reductions. Thus, these reactions could happen spontaneously. The oxidation of the carbon occurred easily in the air, with the reactions being as follows.

$$
\begin{gathered}
\mathrm{C}+\mathrm{O}_{2} \stackrel{\text { Heating }}{\longrightarrow} \mathrm{CO}_{2} \uparrow \\
2 \mathrm{C}+\mathrm{O}_{2} \stackrel{\text { Heating }}{\longrightarrow} 2 \mathrm{CO} \uparrow
\end{gathered}
$$

The reactions (6) and (5) show the sources of carbon monoxide and carbon dioxide required by the reactions (3) and (4) for the methane generation, respectively. However, only a little carbon monoxide occurred in the inorganic testing. It could be because the cotton suffered a complete reaction with the air, and the reaction (6) almost did not happen. Besides, the gas compositions are mainly hydrocarbons with high carbon content, which could promote the reaction (5). The hydrogen was known taking part in the reactions (2), (3) and (4), which was verified in the inorganic resting.

The mixture of hydrogen and carbon monoxide is called water-gas. The reaction (7) happened below $180{ }^{\circ} \mathrm{C}$. The oxygen atom in water molecular reacted with the heated carbon in a short time, producing hydrogen and carbon monoxide, which is called water-gas shift reaction (WGSR). The reaction between water and carbonized cellulose produced hydrogen and carbon monoxide, also produced little carbon dioxide, nitrogen, and methane. These kinds of gas compositions were the raw materials of synthetic ammonia. Therefore, the gaseous products contained some methane and ammonia.

$$
\mathrm{C}+\mathrm{H}_{2} \mathrm{O} \stackrel{\text { WGSR }}{\longrightarrow} \mathrm{CO} \uparrow+\mathrm{H}_{2} \uparrow
$$

The produced hydrogen in the reaction (7) became the reactant of the reactions (2), (3) and (4). However, the hydrogen was not stable in the heated air, and then the reaction (8) happened.

$$
\mathrm{O}_{2}+2 \mathrm{H}_{2} \stackrel{\text { Heat oxidation }}{\longrightarrow} 2 \mathrm{H}_{2} \mathrm{O} \uparrow
$$

Figure 2 shows the pathways of product generation by heating cotton. The carbon, laevoglucose (L-glucose), and water were produced after the dehydration of the cotton. With the action of carboxylic 
acid, the glycosidic bond of L-glucose was broken to produce ketones. Then the acetone was produced. A part of carbon reacted with oxygen, producing carbon monoxide and carbon dioxide. The rest part of carbon took part in the WGSR with water, producing hydrogen. The produced hydrogen reacted with carbon, carbon monoxide, and carbon dioxide, finally producing methane.

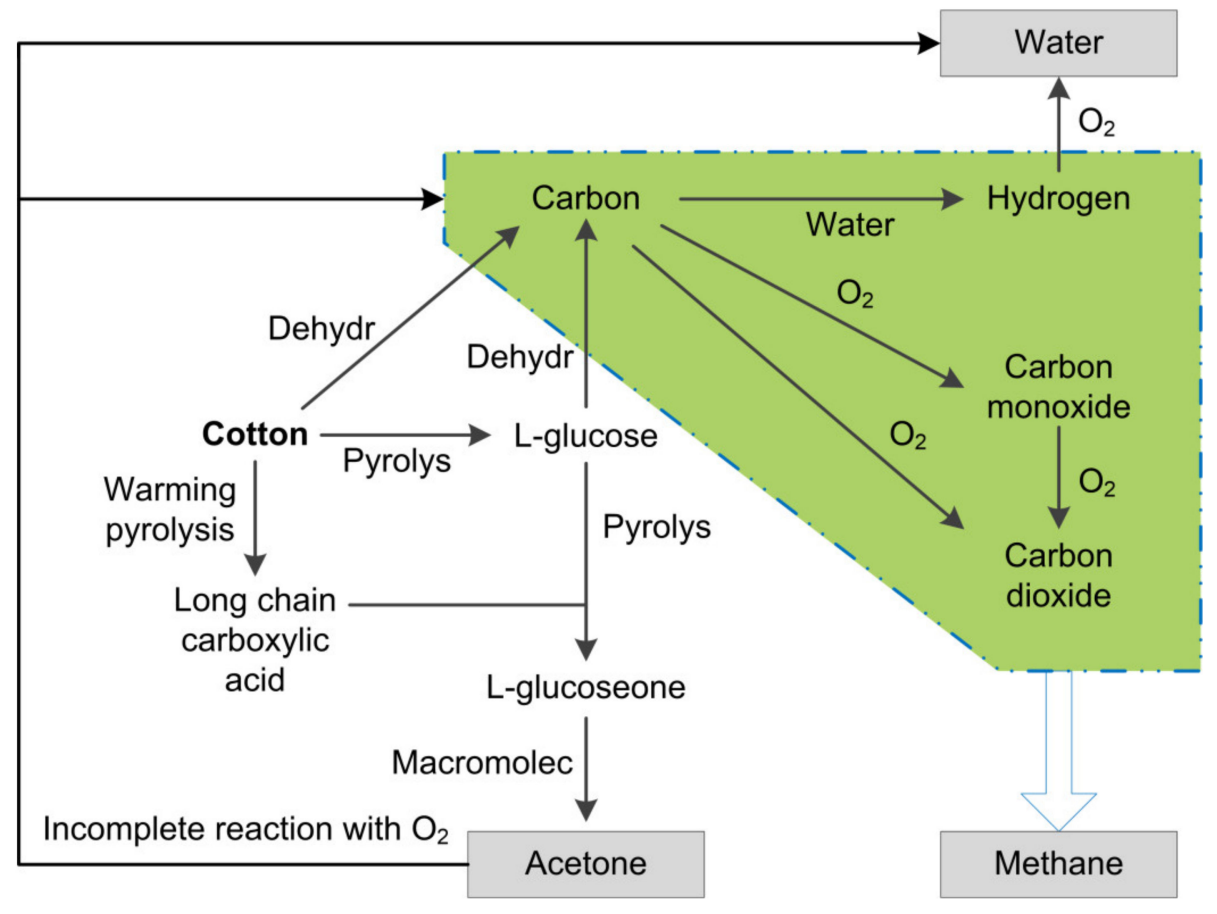

Figure 2. Pathways of product generation.

\subsection{Discussions}

According to the experimental results, the siloxane and polysiloxane were impurities, and not used as iconic gas compositions. The methane had the highest proportion in the organic gases at different temperatures. It could be used as an iconic gas composition. The acetone was the heating process product at $125^{\circ} \mathrm{C}$ and $145^{\circ} \mathrm{C}$. At the early stage of smoldering, the acetone and other ketones were produced via the complicated reactions from the levoglucosenone (L-glucoseone). Therefore, the acetone can also be used as an iconic gas composition. When a temperature increased to $105^{\circ} \mathrm{C}$, the hydrogen was completely reacted with its concentration being 0 . The hydrogen concentration increased first and then decreased with the temperature increasing from $105^{\circ} \mathrm{C}$ to $165^{\circ} \mathrm{C}$. With the temperature increasing to $185^{\circ} \mathrm{C}$, the hydrogen concentration increased once again. Following this law, the early smoldering stage can be judged according to the hydrogen concentration.

In the previous research, only carbon monoxide was considered as an iconic gas composition. The carbon monoxide occurred over $200^{\circ} \mathrm{C}$, and it could be an early warning gas for the presence of flame combustion at over $200{ }^{\circ} \mathrm{C}$. According to the experimental results, the carbon monoxide first occurred at $145^{\circ} \mathrm{C}$, and its concentration decreased to 0 at higher temperatures. The carbon monoxide was produced because of the cotton smoldering at over $145^{\circ} \mathrm{C}$, but its concentration was quite low. It was because that the carbon oxidation reaction was complete, and other organics with high carbon content reacted to mainly generate carbon dioxide. When the temperature continued to rise, the organics with high carbon content were decomposed to alkanes with small molecular weight. The carbon monoxide was also produced during the decomposing process. According to this process, the carbon monoxide could be used as an iconic gas composition. When the carbon monoxide was monitored, the cotton was at the early stage of smoldering. When the concentration of carbon 
monoxide increased, the smoldering turned into fire which was hard to put out. Therefore, firefighting must be conducted as soon as the carbon monoxide appears.

According to the generation of gas compositions, the cotton was at over $90^{\circ} \mathrm{C}$ when the methane was tested. When the methane and hydrogen were tested together, the cotton was at approximately $110^{\circ} \mathrm{C}$. When methane, hydrogen, and acetone were tested at the same time, the cotton was at the early smoldering stage. When methane, hydrogen, and carbon monoxide were tested, the temperature of cotton increased and the cotton smoldering had to be controlled as earlier as possible. To verify the correctness of the above inferences, a thermogravimetric experiment under air atmosphere was conducted. The thermogravimetric curve of heating cotton is shown in Figure 3. When the temperature was below $25^{\circ} \mathrm{C}$ (Area A), the cotton sample did not react with air, thus, the mass of cotton did not change. When the temperature reached $25 \sim 38^{\circ} \mathrm{C}$ (Area B), the mass of cotton increased because of the greater oxygen adsorption capacity than the gas production. When the temperature reached $38 \sim 142{ }^{\circ} \mathrm{C}$ (Area C), the mass of cotton decreased significantly. It might be because as the temperature increased, the moisture in cotton gradually evaporated at high temperature, and at the same time, the $\mathrm{CO}_{2}, \mathrm{CO}$, acetone, and $\mathrm{CH}_{4}$ are generated. The results of the thermogravimetric experiment were consistent with the theoretical analysis. When the temperature exceeded $142{ }^{\circ} \mathrm{C}$ (Area D), there was almost no moisture in the cotton. Meanwhile, the oxygen adsorption of the cotton sample continued with its capacity greater than the gas production. Thus, the mass of cotton increased slightly.

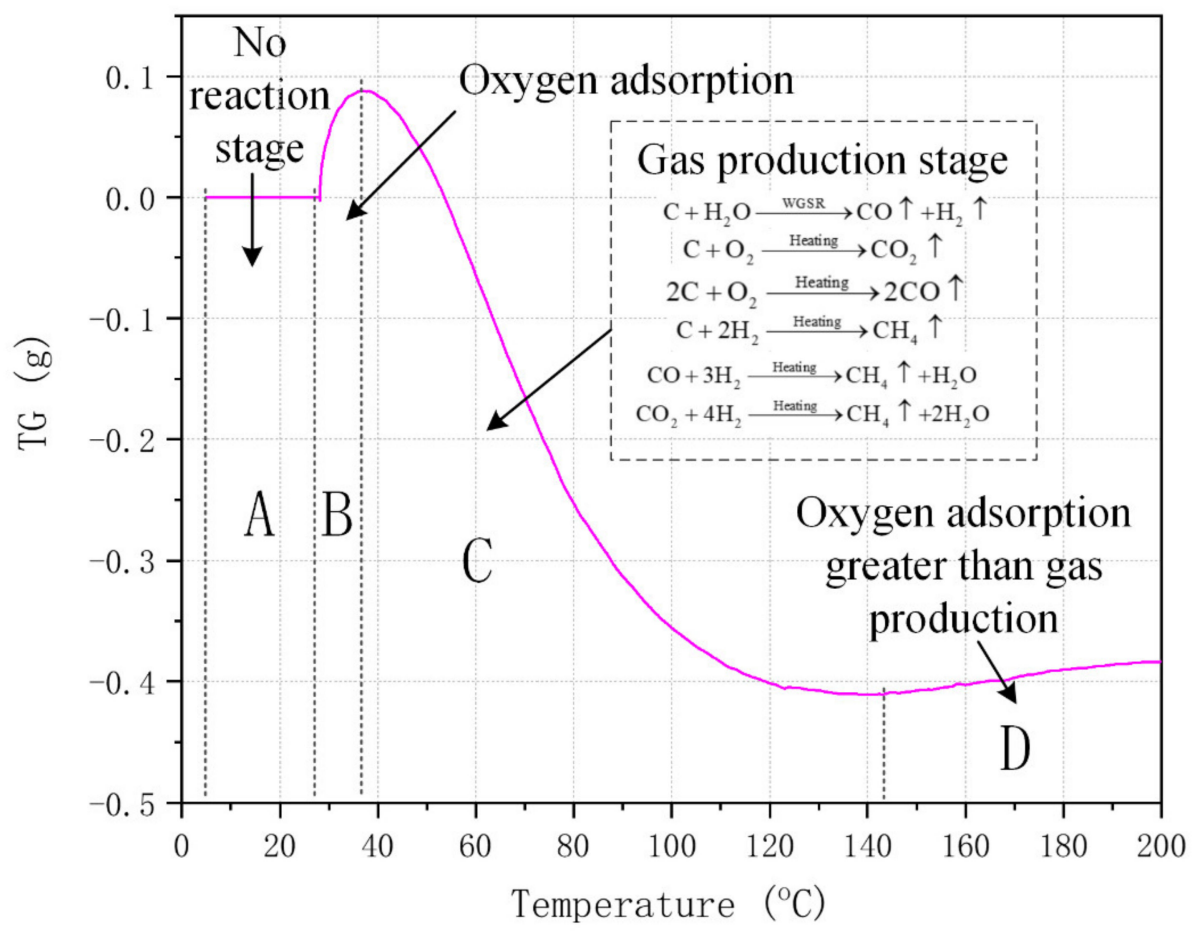

Figure 3. Thermogravimetric analysis of the cotton sample.

\section{Conclusions}

In this work, the mini tube furnace was used to heat a cotton sample, and the GC/MS was utilized to analyze the produced organic and inorganic gas compositions. According to the concentration changes in the gas compositions at different temperatures, the following conclusions are drawn:

(1) The alkanes, furans, alkenes, aldehydes, hydrazines, and acids were produced during the heating process, while they could not be regarded as iconic gas compositions because of their little proportion. The methane has the highest proportion being nearly $99 \%$ in the organic 
gas compositions. The produced inorganic gas compositions contained a little hydrogen and carbon monoxide.

(2) Methane was produced continuously during the heating process. At $95^{\circ} \mathrm{C}$, a small quantity of hydrogen occurred as a mid-product. The acetone was produced at $125^{\circ} \mathrm{C}$ with the generation of hydrogen. A tiny amount of carbon monoxide is produced at $145^{\circ} \mathrm{C}$, showing the smoldering was at the early stage.

(3) The joint detection of the methane and hydrogen could be used to predict if the smoldering happened. The produced acetone and carbon monoxide could be used to confirm the smoldering stage. Therefore, this study on the iconic gas compositions will provide a significant base for the prevention of cotton fires.

Author Contributions: Methodology, H.S. and J.L.; validation, J.S. and J.F.; formal analysis, H.J. and J.L.; investigation, J.S. and J.F.; data curation, H.J.; writing—original draft preparation, H.S.; writing-review and editing, H.J.; visualization, H.S.; supervision, H.J.; funding acquisition, H.S. All authors have read and agreed to the published version of the manuscript.

Funding: This research was funded by the Fundamental Research Funds for the Central Universities [2652018098] and the Cultivation Fund from the Key Laboratory of Deep Geodrilling Technology, Ministry of Natural Resources [PY201902]. And The APC was funded by the Fundamental Research Funds for the Central Universities [2652018098].

Acknowledgments: This work is supported by the Fundamental Research Funds for the Central Universities [2652018098], the Cultivation Fund from the Key Laboratory of Deep Geodrilling Technology, Ministry of Natural Resources [PY201902].

Conflicts of Interest: The authors declare no conflict of interest.

\section{References}

1. Dong, C.; Lu, Z.; Zhang, F.; Zhu, P.; Wang, P.; Che, Y.; Sui, S. Combustion behaviors of cotton fabrics treated by a novel nitrogen- and phosphorus-containing polysiloxane flame retardant. J. Therm. Anal. Calorim. 2015, 123, 535-544. [CrossRef]

2. Zhang, W.; Liu, C.; Zheng, X.; Wang, K.; Cui, F.; Wang, R.; Zhu, J. Using a modified DNDC biogeochemical model to optimize field management of a multi-crop (cotton, wheat, and maize) system: A site-scale case study in northern China. Biogeosciences 2019, 16, 2905-2922.

3. Hagen, B.C.; Frette, V.; Kleppe, G.; Arntzen, B.J. Onset of smoldering in cotton: Effects of density. Fire Saf. J. 2011, 46, 73-80.

4. Hagen, B.C.; Frette, V.; Kleppe, G.; Arntzen, B.J. Effects of heat flux scenarios on smoldering in cotton. Fire Saf. J. 2013, 61, 144-159.

5. Madsen, D.; Azeem, H.A.; Sandahl, M.; van Hees, P.; Husted, B. Levoglucosan as a tracer for smouldering fire. Fire Technol. 2018, 54, 1871-1885. [CrossRef]

6. Travers, E.B.; Olsen, N.F. Effect of air permeability on smoldering characteristics of cotton upholstery fabrics. Text. Res. J. 1982, 52, 598-604.

7. Wakelyn, P.J.; Hughs, S.E. Evaluation of the flammability of cotton bales. Fire Mater. 2002, 26, $183-189$.

8. Donaldson, D.J.; Yeadon, D.A.; Harper, R.J. Smoldering phenomenon associated with cotton. Text. Res. J. 1983, 53, 160-164. [CrossRef]

9. Kellogg, D.S.; Waymack, B.E.; McRae, D.D. The Initiation of Smoldering Combustion in Cellulosic Fabrics. J. Fire Sci. 1998, 16, 90-104. [CrossRef]

10. Li, H.W.; Yue, Y.T.; Li, Y.X.; Zhang, H. The determination of the heat release rate on cotton smoldering fire and polyurethane fire. Adv. Mater. Res. 2013, 668, 915-919.

11. Li, W.; Liu, W.; Ni, Z. An experimental investigation of the smoldering combustion of cotton with different moisture contents. AEIC Academic Exchange Information Centre (China). In Proceedings of the 2nd International Workshop on Advances in Energy Science and Environment Engineering (AESEE 2018) (Advances in Energy Science and Environment Engineering II), AEIC Academic Exchange Information Centre (China), International Conference on Humanities and Social Science Research, Zhuhai, China, 2-4 February 2018; pp. 447-456. 
12. Hagen, B.C.; Frette, V.; Kleppe, G.; Arntzen, B.J. Transition from smoldering to flaming fire in short cotton samples with asymmetrical boundary conditions. Fire Saf. J. 2015, 71, 69-78. [CrossRef]

13. Xie, Q.; Zhang, Z.; Lin, S.; Qu, Y.; Huang, X. Smoldering fire of high-density cotton bale under concurrent wind. Fire Technol. 2020. [CrossRef]

14. Xu, Q.; Yang, S.; Tang, Z.; Cai, J.; Zhong, Y.; Zhou, B. Free radical and functional group reaction and index gas CO emission during coal spontaneous combustion. Combust. Sci. Technol. 2018, 190, 834-848. [CrossRef]

15. Su, H.; Zhou, F.; Li, J.; Qi, H. Effects of oxygen supply on low-temperature oxidation of coal: A case study of Jurassic coal in Yima, China. Fuel 2017, 202, 446-454. [CrossRef]

16. Su, H.; Ji, H.; Chen, X. Model simplification of coal combustion kinetics: A case study of Weihuliang coal in Urumchi, China. Combust. Theory Model. 2019, 23, 1071-1089. [CrossRef]

17. Feng, K.K. Spontaneous combustion of Canadian coals. CIM Bull. 1985, 78, 71-75.

18. Hu, X.; Yang, S.; Zhou, X.; Yu, Z.; Hu, C. Coal spontaneous combustion prediction in gob using chaos analysis on gas indicators from upper tunnel. J. Nat. Gas Sci. Eng. 2015, 26, 461-469. [CrossRef]

19. Horrocks, A.R.; Price, D.; Akalin, M. FTIR analysis of gases evolved from cotton and flame retarded cotton fabrics pyrolysed in air. Polym. Degrad. Stab. 1996, 52, 205-213. [CrossRef]

20. Furneaux, R.H.; Gainsford, G.J.; Shafizadeh, F.; Stevenson, T.T. Synthesis and thermal chemistry of isolevoglucosenone. Carbohydr. Res. 1986, 146, 113-128. [CrossRef]

21. Shafizadeh, F.; Furneaux, R.H.; Stevenson, T.T. Some reactions of levoglucosenone. Carbohydr. Res. 1979, 71, 169-191. [CrossRef]

22. Halpern, Y.; Riffer, R.; Broido, A. Levoglucosenone (1,6-anhydro-3,4-dideoxy-.DELTA.3-.beta.-D-pyranosen-2one). Major product of the acid-catalyzed pyrolysis of cellulose and related carbohydrates. J. Org. Chem. 1973, 38, 204-209. [CrossRef]

(C) 2020 by the authors. Licensee MDPI, Basel, Switzerland. This article is an open access article distributed under the terms and conditions of the Creative Commons Attribution (CC BY) license (http://creativecommons.org/licenses/by/4.0/). 